\title{
АРХЕОЛОГИЧЕСКИЕ РАБОТЫ НА ГОРОДИЩЕ КУЛЬТОБЕ АРЫССКОМ, МОГИЛЬНИКАХ КУЛЬТОБЕ И КЫЛЫШЖАР В 2016-2017 гг.
}

\author{
(C) 2018 г. А.Н. Подушкин
}

Статья посвящена анализу материалов новых археологических комплексов городища Культобе арысского, катакомб могильников Культобе 2 и Кылышжар, полученных в результате работ 2016-2017 гг. Приводится полная характеристика находок, освещаются вопросы хронологии и этнокультурной принадлежности изучаемых памятников, которые позволяют связать их с государством Кангюй и датировать I в. до н.э. - III в. н.э.

Ключевые слова: археология, Южный Казахстан, арысская культура, катакомбные погребения, сарматы, Кангюй, культобинское письмо

Регион Южного Казахстана это контактная зона, на которой две с лишним тысячи лет назад начала складываться городская культура, и которая была объектом местожительства и миграции многочисленных племён номадов. Кроме всего, Южный Казахстан располагался на одной из ветвей Великого Шёлкового пути, что определяло его особый статус в мировой транзитной торговле между государствами западного мира и цивилизациями Древнего Востока. Особый интерес в этом плане представляют археологические объекты первых веков до н.э. - первых веков н.э., когда история региона была связана с первыми союзами племён и государственными объединениями (Канцзюй-Кангюй, сюнну, азиатские сарматы).

Археологический отряд ЮжноКазахстанского государственного педагогического университета в полевых сезонах 2016-2017 гг. продолжил исследования объектов периода государства Кангюй. Стационарным раскопкам подверглись эталонное городище Культобе арысской культуры Южного Казахстана, а также два могильника - Культобе 2 и Кылышжар. Публикация посвящена основным результатам этих работ в контексте общего анализа археологического материала, историко-культурных и хронологических интерпретаций. \section{хеологии}

\section{1. Раскопки памятников ар-}

Городище Культобе арысское расположено в пойме реки Арысь, на её левом берегу, вблизи старого русла (Ордабасинский район, ЮКО), в 4 км к С3 от пос. Сарыарык. Объект представляет собой двухчастное городище с рабадом. Цитадель памятника практически уничтожена паводковыми водами р. Арысь, оставшаяся часть представляет собой небольшой сегмент с обрывистым юго-западным склоном. В разрезе склона отмечены строительные конструкции из пахсы, 
трапециевидного кирпича-сырца (части кладки крепостной стены). Рабад городища Культобе имеет неправильную трапециевидную планировку, в центральной и северной частях рабада фиксируется понижение, которое придает ему «П»-образный вид. В южной части рабада отмечены округлые возвышения - судя по всему, это остатки оборонительных башен. Между цитаделью и рабадом отмечена площадкапонижение и ров (рис. 1, 1).

В 2017 г. на рабаде городища был заложен новый раскоп размерами $10 \times 5$ м, западная часть которого (5×5 м) вскрыта по всей площади на глубину 1,8-1,95 м (уровень основного строительного горизонта периода государства Кангюй I в. до н.э. - IV в. н.э.). Здесь открыты пахсовые стены одного большого жилого помещения прямоугольной планировки, где зафиксирована пахсовая суфа-платформа, в которую помещён стоящий вертикально хум (рис. 1, 2). В результате работ получен большой по объёму и историко-культурной важности археологический материал, включающий в основном керамику различного функционального назначения: хозяйственно-бытовую (восстанавливаемые формы и фрагменты от крупных сосудов - хумов, хумчи, тазиков-тагара) (рис. 2, 1-4, 8), столовую (фрагменты от кувшинов, горшков, чаш) (рис. 3, 1-4) и кухонную посуду (фрагменты от сковород, горшков) (рис. 2, 5-7). Заслуживают внимания хум и кувшин с сарматскими знаками-тамгами, прорисованными по сырой глине до обжига изделий (рис. 3, 1; 4, 1).

Особый интерес представляют две неординарные находки. Одна из них это фрагмент кангюйского (культобинского) письма на керамических кирпичах-таблицах. Он включает 10 хорошо читаемых, шесть частично восстанавливаемых знаков, оформленных в четыре строки (рис. 4, 3). Вторая связана с обнаружением бронзовой монеты, относящейся к Великой Кушанской империи (да-юэчжи китайских источников) (рис. 4, 2). Отметим, что все три находки обнаружены в одном культурном слое (рис. 4).

Могильник Культобе 2 находится на гребневидных лессовых останцах правой надпойменной террасы p. Арысь, в 2,5 км к северу от городища Культобе и представляет собой вариант могильника, сочетающего в себе расположение цепочкой и бессистемного расположения насыпей. Он включает 18 курганов, планировка насыпей которых каплевидная, со смещенной от центра максимальной точкой по высоте; наиболее крутой склон северный, реже - восточный. Насыпи курганов сложены из лёсса, средние размеры курганов могильника Культобе 2: диаметр в основании от 5 до 16 м, высота от 0,5 до 1,5 м.

Курган 2. В юго-западном секторе под насыпью, на глубине 3,4 м открыта «Т»-образная двухчастная катакомба, которая включает узкотраншейный дромос и сводчатую полую погребальную камеру прямоугольной планировки со сглаженными углами. Вся конструкция вытянута по линии С-Ю, на дне камеры открыто потревоженное древними грабителями одиночное погребение женщины среднего возраста (рис. 5). Обряд погребения: трупоположение на спине изголовьем на ЮВ.

Погребальный инвентарь представлен следующими артефактами:

- кувшин кухонный грушевидной формы с высокой горловиной, выраженными плечиками и вертикальной петлевидной ручкой на тулове сосуда. Изделие выполнено из доста- 
Подуикин А.Н. Археологические работы на городище Культобе арысском, могильниках Культобе...
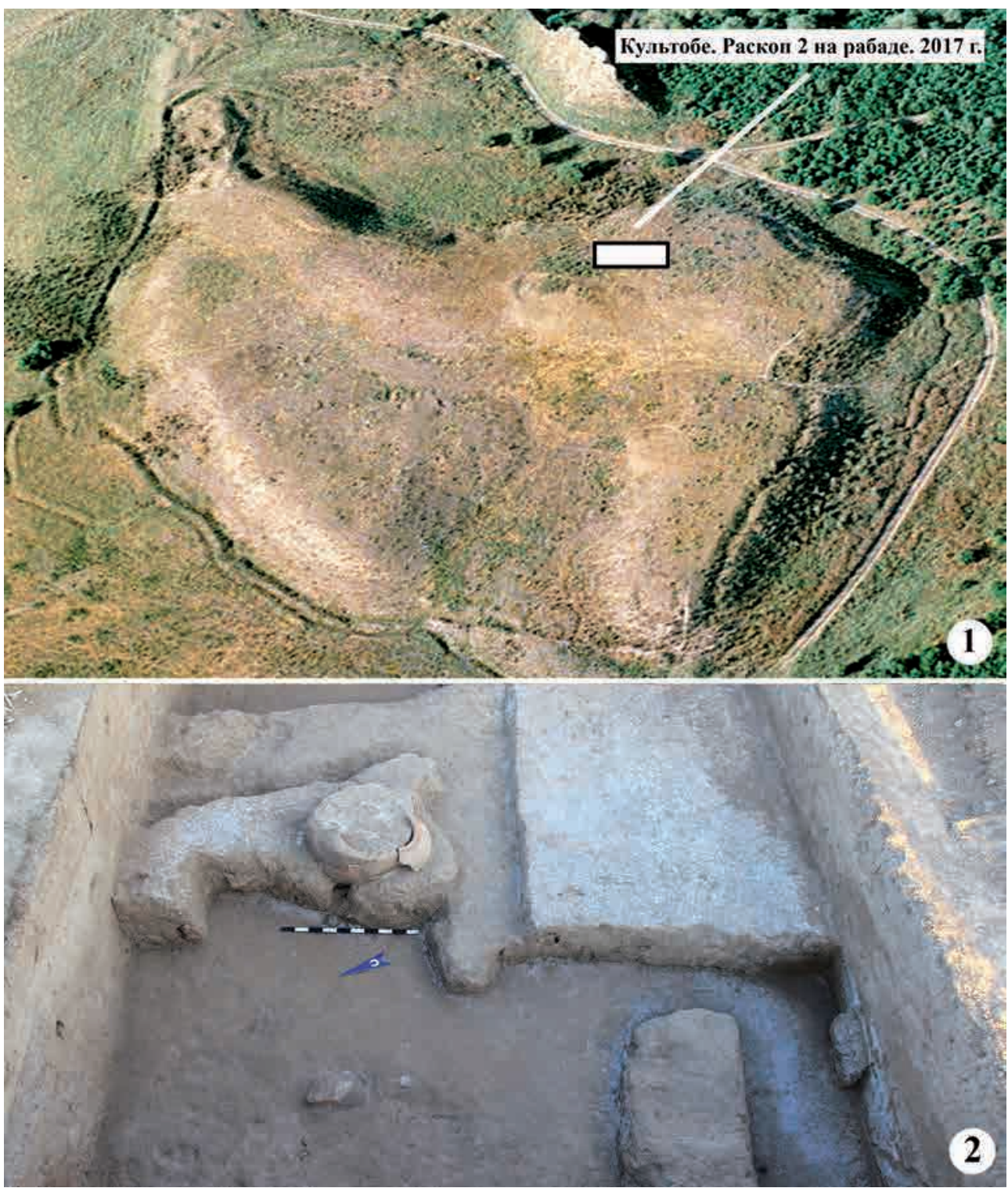

Рис. 1. Городище Культобе и внешний вид раскопа 2 на рабаде 20172. Фото автора

Fig. 1. The site of ancient settlement Kultobe and excavation site 2 in Rabad, 2017. Фото автора

точно грубого теста с примесями песка, шамота, оно носит следы древней реставрации (зафиксированы более 10 высверленных отверстий в стенке сосуда по краям трещин), его поверхность закопчена (свидетельство прямого использования на очаге). Декор отсутствует (рис. 5, 1).
- крышка округлая из необожжённой глины, которая располагалась на венчике кувшина, но затем была смещена вниз (рис. 5, 2).

- железный безлопастной наконечник стрелы (рис. 5, 3), железный стержень неизвестного назначения (рис. 5, 4) и перстень железный с 


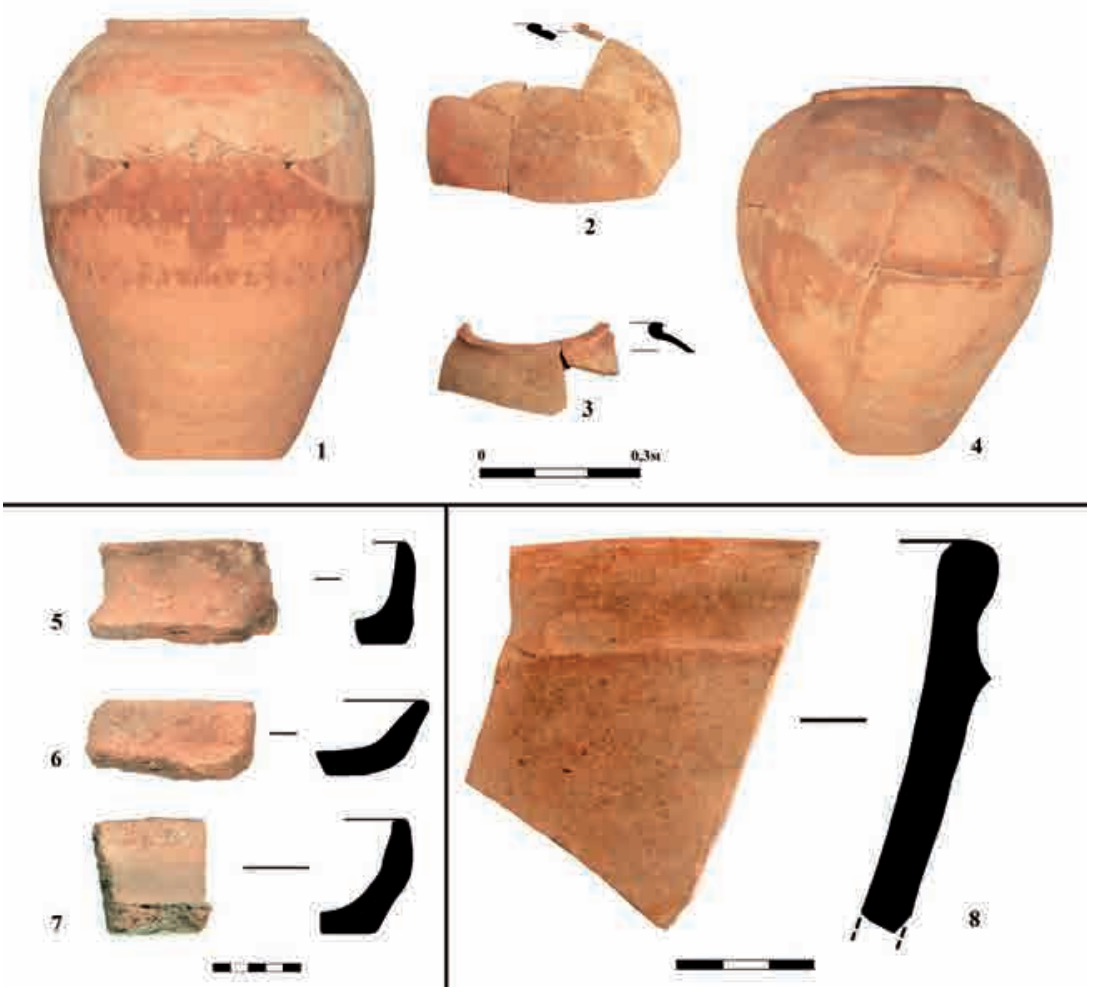

Рис. 2. Хозяйственно-бытовая и кухонная керамика Культобе арысского

Fig. 2. Household and kitchen ceramics of the Arys Kultobe

бронзовой выпуклой печаткой, которая представляет собой группу спаянных небольших шариков в виде пирамиды (рис. 5, 5).

- пряжка железная круглая рамчатая с подвижным язычком (рис. 5,6 ) и округлая бусина из стекла со сквозным отверстием (рис. 5, 7).

Местонахождение инвентаря следующее: кувшин кухонный керамический находился в вертикальном положении слева от костяка; рядом обнаружена крышка из необожжённой глины (рис. 5, 1-2); железный наконечник стрелы найден у кисти левой руки костяка (рис. 5, 3); железный стержень, перстень, железная круглая пряжка и стеклянная бусина компактной группой располагались в районе таза костяка (рис. 5, 4-7).
Могильник Кыльишжар зафиксирован в 1,5 км к Ю3 от городища Культобе, в непосредственной близости от сегментовидного обрыва правого берега р. Арысь, на лёссовой надпойменной террасе, которая в этом месте по высоте плавно сходит на нет, опускаясь «сверху-вниз» к руслу реки. Насыпи расположены бессистемно, в отдельных группах курганов фиксируется планировка в «цепочку»; в целом могильник Кылышжар протянулся более чем на 1,5 км в направлении СВ-Ю3. Могильник включает от 60 до 80 курганов. Планировка насыпей различная: встречены каплевидные, со смещенной от центра максимальной точкой по высоте курганы; наиболее крутой склон северный, 


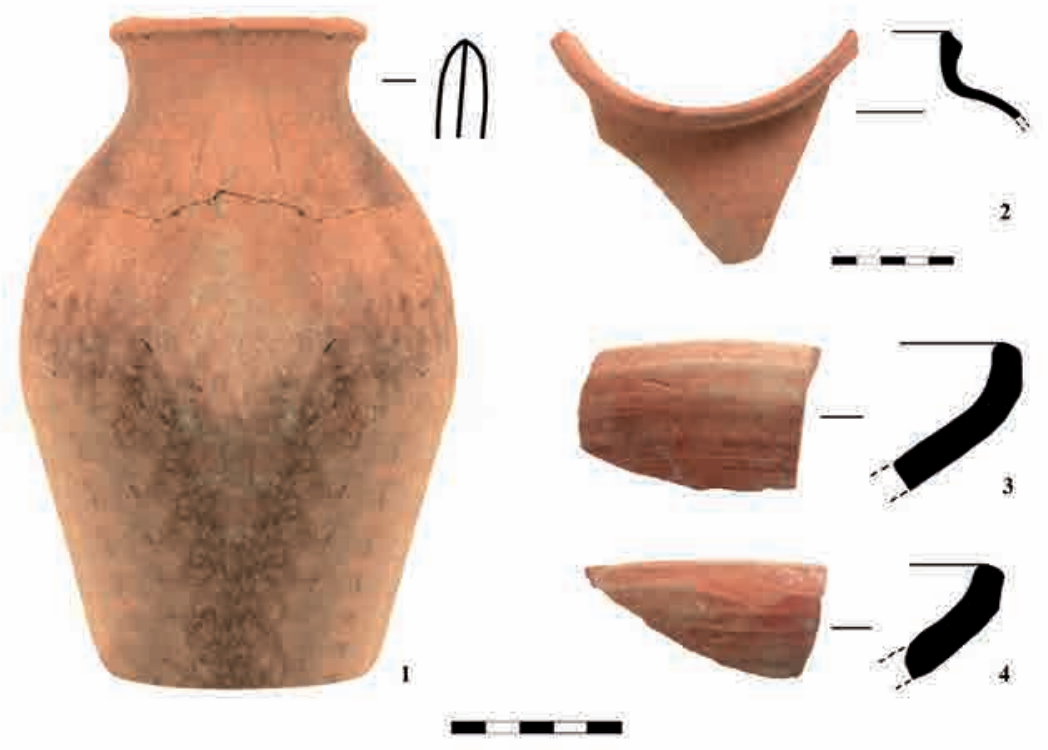

Рис. 3. Столовая керамика Культобе арысского

Fig. 3. Dining ceramics of the Arys Kultobe

реже - восточный. Имеются также округлые насыпи, с пологими, почти не выраженными склонами. Все курганы однородны по составу (сложены из лёсса), их средние размеры от 8-10 до 30 и более метров в основании при высоте от 0,8 до 2,5 м.

В течение полевого сезона 2017 года на могильнике Кылышжар раскопкам подверглись курганы 1 и 2 юго-западной группы насыпей, которая включает более 25 курганов (некоторые насыпи носят следы ограбления в древности).

Курган 1. Почти в центре под насыпью обнаружена погребальная «Т»-образная трёхчастная катакомба «с дромосом с заплечиками», которая конструктивно включает: основной дромос в виде большой грунтовой прямоугольной ямы; малый узкотраншейный дромос, вырезанный в полу основного дромоса; аркообразный проём, связывающий малый дромос с погребальной камерой (проём зало- жен горизонтальными рядами прямоугольным кирпичём-сырцом); сводчатую полую погребальную камеру трапециевидной планировки (в западной стенке камеры, на уровне пола, отмечена вырезанная в лёссе ниша).

Вся конструкция вытянута по линии С-Ю, на дне камеры открыто коллективное погребение, включающее четыре костяка (два мужских, один женский и один девочкиподростка): два из них расположены вдоль северной, восточной стенок камеры, один - в центре и один у места соединения малого дромоса и заложенного кирпичом-сырцом проёма (рис. 6). Обряд погребения: трупоположение на спине изголовьем преимущественно на восток.

В числе иных особенностей обряда отметим факт фиксации остатков прямоугольного деревянного (судя по всему, плетёного) гроба, в котором находился костяк 1 , а также - наличие «жертвенной пищи» в виде передней 


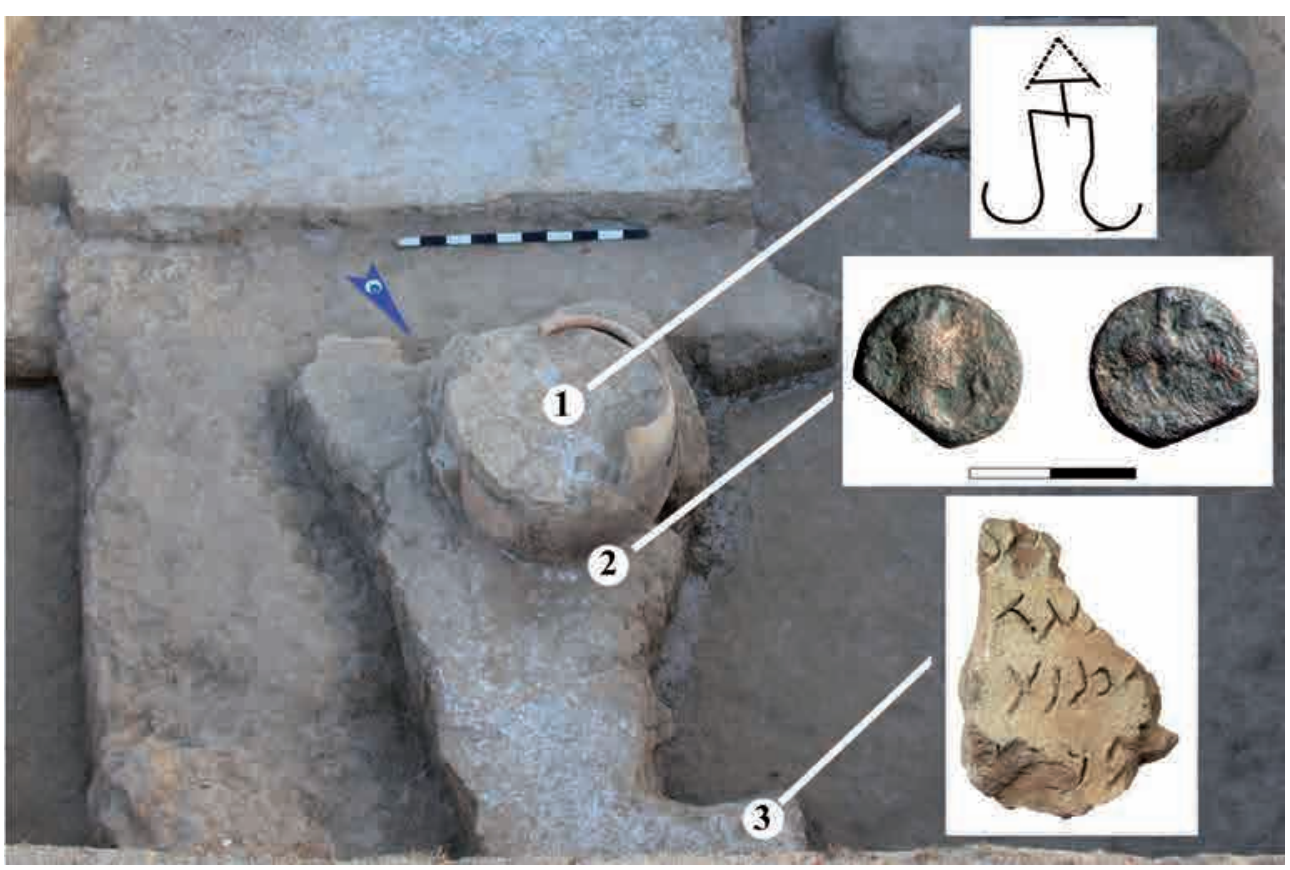

Pис. 4. Раскоп 2 на рабаде городища Культобе, 2017 г.: хум со знаком-тамгой, фрагмент письменности и медная монета

Fig. 4. Excavation 2 on the Rabad of the Kultobe settlement, 2017: hum with a tamga sign, a fragment of writing and a copper coin

части туши овцы (барана) вблизи ног этого костяка (рис. 6).

Погребальный инвентарь представлен следующими артефактами:

- кувшин столовый керамический грушевидной формы с высокой горловиной, выраженными плечиками и вертикальной петлевидной ручкой на тулове сосуда. Изделие выполнено на гончарном круге из качественного теста, хорошего обжига. Сосуд покрыт светло-жёлтым ангобом, а в нижней части украшен светло-коричневым ангобом (рис. 6, 1).

- серебряная пластина-оклад венчика деревянного сосуда; пластина крепилась на венчике посредством серебряных гвоздиков с круглыми шляпками (всего 16 гвоздиков; рис. 6, 3) и серебряная декоративная пластина прямоугольной формы на кожаное изделие с четырьмя штырьками- фиксаторами и овальной заклёпкой с обратной стороны (рис. 6, 2).

- серьга бронзовая петлевидная из круглой проволоки с окончанием в виде приплюснутой лопатки (рис. 6, 6), две петлевидные бронзовые подвески из прямоугольной в разрезе проволоки с приплющенными окончаниями, соединёнными вместе (рис. 6, 4-5) и круглая серебряная ворворка (рис. 6, 7).

Местонахождение инвентаря следующее: кувшин столовый керамический находился в вертикальном положении вблизи задних конечностей костяка 1; у черепной коробки костяка 1, справа, обнаружены серебряная пластина-оклад и декоративная серебряная пластина; бронзовая серьга находилась справа черепной коробки костяка 2; в верхней части черепной коробки костяка 2 найдена 
Подуикин А.Н. Археологические работы на городище Культобе арысском, могильниках Культобе...

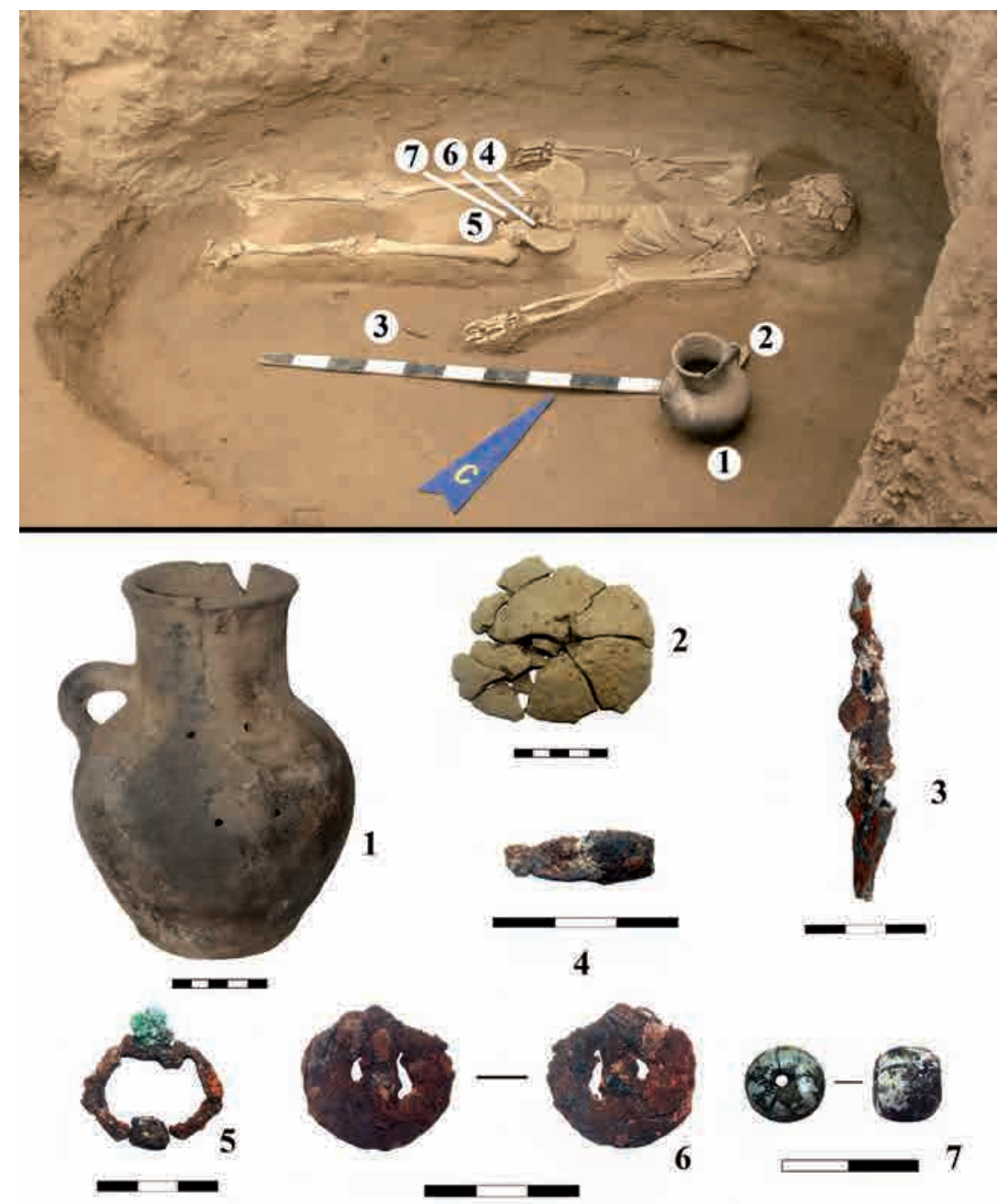

Рис. 5. Могильник Культобе 2. Погребение, инвентарь в катакомбе 2

Fig. 5. Burial Kultobe 2. Burial, inventory in the catacomb 2

бронзовая ворворка; в районе таза костяка 2 зафиксированы две бронзовые петлевидные подвески (рис. 6).

Курган 2. В центре под насыпью, с незначительным смещением в западный сектор, на глубине 3,5 м от уровня дневной поверхности была обнаружена «Т»-образная трёхчастная катакомба с узкотраншейным дромосом, которая включает узкотраншейный бесступенчатый дромос, аркообразный в разрезе лаз, связывающий дромос с погребальной камерой (проём лаза в древности был заложен прямоуголь- ным кирпичом-сырцом) и сводчатую полую овально-прямоугольной планировки погребальную камеру.

Катакомба вытянута по линии $\mathrm{C}-\mathrm{O}$, на дне камеры открыто одиночное погребение, сильно потревоженное древними грабителями: разрушенные останки костяка и погребального инвентаря в беспорядке располагались на полу у восточной стенки камеры (рис. 7, I.1).

Обряд погребения (предположительно): трупоположение на спине. В числе иных особенностей обря- 


\section{ҚАЗАҚСТАН АРХЕОЛОГИЯСЫ № 1-2 2018}
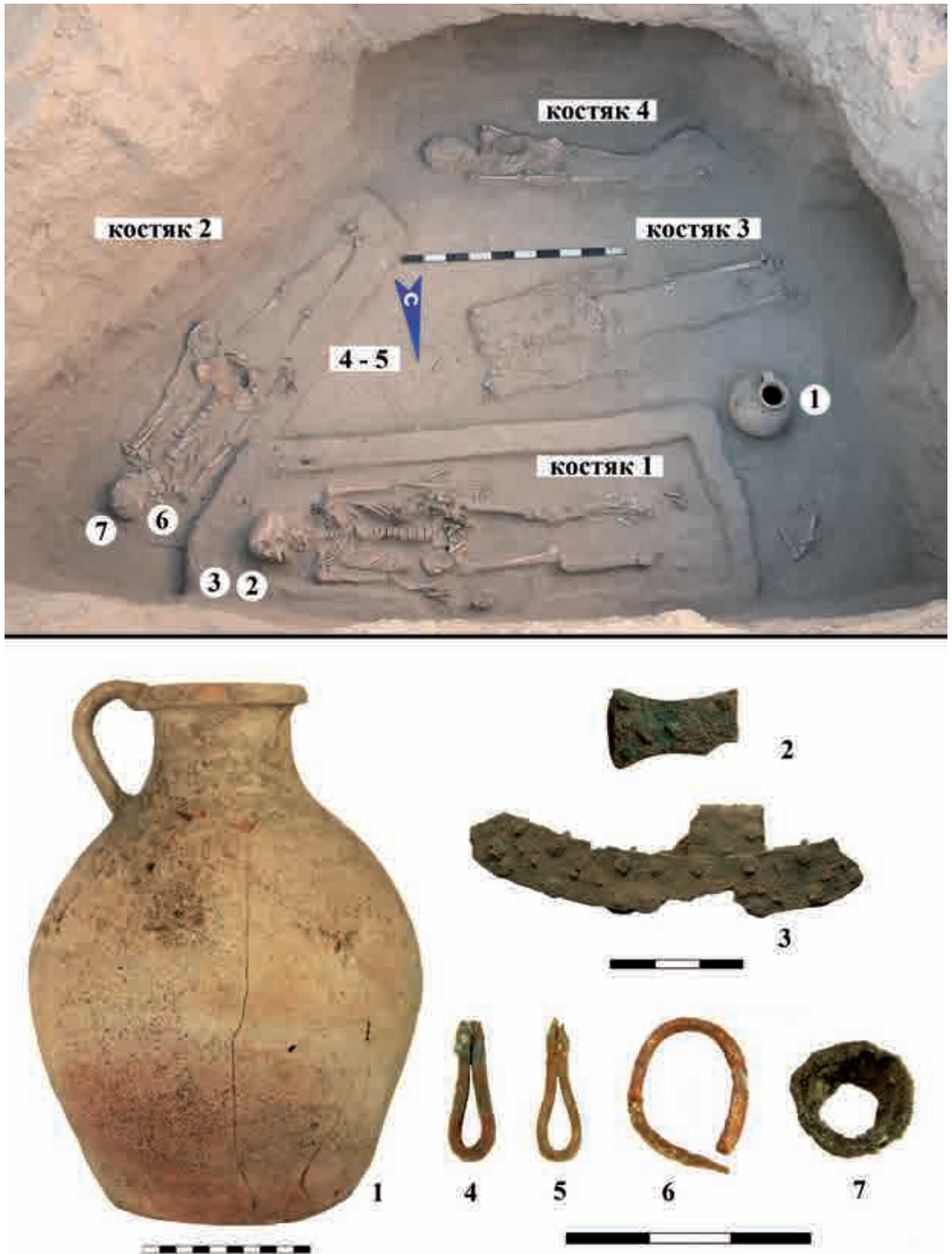

Рис. 6. Могильник Кылышжар, юго-западная группа курганов. Катакомба 1 (погребение, инвентарь)

Fig. 6. Kylyshjar burial ground, southwestern group of mounds. Catacomb 1 (burial, inventory)

да отметим факт фиксации фрагментов дерева и угля, а также - наличие костных останков от овцы (барана).

Погребальный инвентарь представлен следующими артефактами:

- кувшин столовый керамический грушевидной формы, с выраженной горловиной без ручек. Сосуд выполнен из качественного, почти без примесей, теста, на быстро вращающемся гончарном круге, обжи- га хорошего. Кувшин декорирован красно-коричневым ангобом, поверх которого в нижней части сосуда, начиная от плечиков, нанесён чёрный ангоб посредством погружения кувшина в ангобную массу (за счёт этой манипуляции образовался ровный поясок, разделяющий два цвета ангоба). Кроме всего, вся поверхность сосуда украшена брызгами насыщенного чёрного ангоба (рис. 7, I.2). 
Подуикин А.Н. Археологические работы на городище Культобе арысском, могильниках Культобе...

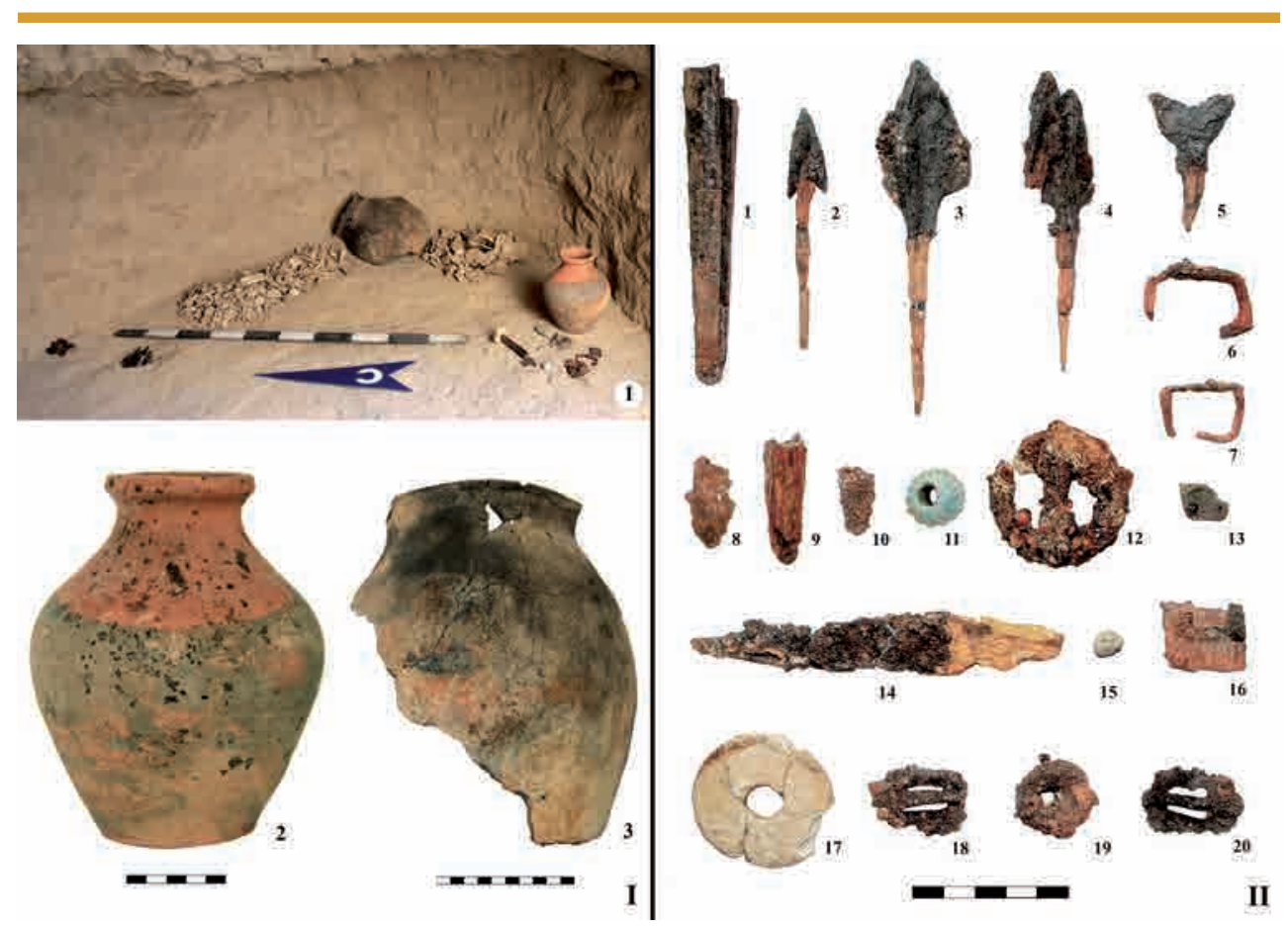

Рис. 7. Могильник Кыльшжар, юго-западная группа курганов. Катакомба 2 (погребение, инвентарь)

Fig. 7. Kylyshjar burial ground, southwestern group of mounds. Catacomb 2 (burial, inventory)

- части венчика и боковины крупного кухонного грушевиднобанкообразного горшка без ручек (форма восстанавливается). Сосуд сделан вручную из грубого, с большими примесями дресвы, шамота и растительности теста; обжига кострового. Нижняя часть горшка покрыта ангобом жёлто-коричневого цвета, внешняя поверхность носит следы использования на открытом огне (закопчена; рис. 7, I.3).

- железные черешковые трёхлопастные наконечники стрел с опущенными и прямыми жальцами (4 экз.) (рис. 7, II.2-4) и железный черешковый двулопастной вильчатый наконечник стрелы (рис. 7, II.5); на черешках всех наконечников отмечены следы от деревянных древков);

- железный черешок кинжала (рис. 7: II.1), круглое каменное на- вершие от него с отверстием в центре (рис. 7: II.17), две железные скобы (рис. 7: II.6-7) и железные окончания от черешков ножей (кинжалов) (рис. 7: II.8-10);

- крупная круглая железная пряжка с подвижным язычком (атрибут конской экипировки) (рис. 7: II.12), две прямоугольные железные пряжки с подвижным язычком (атрибуты кожаной обуви) (рис. 7: II.18, 20) и круглая железная пряжка без язычка (рис. 7, II.19);

- часть железной втулки с остатками дерева (атрибут ножен кинжала) (рис. 7: II.16) и часть бронзовой декоративной пластины со шляпками от заклёпки (рис. 7: II.13);

- крупная ребристая бусина из египетского фаянса (рис. 7: II.11) и небольшой фрагмент мела (рис. 7: II.15). 


\section{2. Вопросы хронологии}

В контексте хронологии остановимся на некоторых аналогиях и параллелях археологическому материалу из городища Культобе арысского и катакомб могильника Культобе 2 и Кылышжар. В качестве уверенных хроно-индикаторов выступают нумизматическая находка и несколько значимых артефактов, дающих основание для соответствующих выводов. В их числе железные наконечники стрел, часть кинжала (черешок и каменное навершие рукояти), серебряная обкладка венчика деревянного сосуда, ребристая бусина из египетского фаянса.

Несомненно, самой важной их них является медная монета. Метрические и сюжетно-иконографические составляющие этой монеты позволяют связывать её с множественной эмиссией в недавнем прошлом безымянного кушанского правителя из серии «Soter Megas», которая в свете новых данных принадлежит второму кушанскому царю, сыну основателя империи Куджулы Кадфиза, Вима I Такто, правившему в 80-90 годы I века н.э. [Ртвеладзе, 2002, с. 141-144].

В качестве датирующего материала из катакомб Южного Казахстана однозначно выступают железные черешковые наконечники стрел с «опущенными» и прямыми жальцами, которые широко встречаются в погребальных памятниках сарматов I в. до н.э. - III в. н.э. [Хазанов, 1971, с. 39; табл. XX, 20-21; табл. XXI, 22, 24; Скрипкин, 1990, с. 135-141; рис. 24, 33, 35-36, 54; Мошкова, 1989а, с. 185; табл. 81, 11, 16, 37, 40б; Симоненко, 2010 , с. $96-99$; рис. 68,1 , 3; рис. 69]. Подобные железные черешковые трёхлопастные наконечники стрел находят аналогии и в среднеазиат- ских материалах первых веков до н.э. - первых веков н.э. [Литвинский, 1965, с. 77-81; рис. 4; Горбунова, 2000, с. $40-41$; рис. $1,3,5,16$; рис. $2,1,4]$.

Железные мечи и кинжалы без навершия и перекрестия характерны для конца среднесарматской и всей позднесарматской культуры рубежа - III в. н.э. [Мошкова, 1989б, с. 195 197, табл. 81, 59, 60-61; Симоненко, 2010 , с. 46 , рис. 29-30; рис. 37: мечи «с рукоятью-штырём» 2-го типа]; зафиксированы они в указанное время и в погребальных памятниках Средней Азии [Обельченко, 1972, с. 57-62, рис. 1; 1973, с. 159-171: курганы 1, 2, 6 и 8 Агалыксайского могильника, могильники близ Самарканда, которые датируются первыми веками до н.э. - первыми веками н.э.; Обельченко, 1978, с. 119-121], Средней Сырдарьи [Максимова и др., 1968, с. 184; рис. 3; табл. IV, 1; 3).

Аналогии серебряной обкладке на венчик деревянного сосуда имеются в материалах могильника Покровка 10 позднесарматского времени (Южное Приуралье, II-III вв. н.э.) [Малашев, Яблонский, 2008, с. 50; рис. $155,1-3]$.

К числу других базовых хроноиндикаторов следует отнести большую ребристую бусину из египетского фаянса. Подобные бусины в сочетании с другими изделиями из египетского фаянса в составе наборных ожерелий и ручных браслетов широко распространены в среде сарматов Евразии в I в. до н.э. - III в. н.э. [Алексеева, 1975 , с. $25 ; 1984$, с. 237 ; Мошеева, 2010, с. 152; Литвинский, Седов, 1984, с. 64].

Отметим также уникальный факт местонахождения в одном культурном слое на городище Культобе арысском одновременно трёх значимых в контексте хронологии и куль- 
Подушкин A.H. Археологические работы на городище Культобе арысском, могильниках Культобе...

турного наполнения находок (хум с сарматским знаком, медная монета и фрагмент кангюйского письма), который позволяет уверенно датировать их концом I в. н.э. (рис. 4).

Корреляция приведённых выше аналогий и хронологических выкладок позволяют отнести новые археологические материалы из памятников Южного Казахстана ко времени I в. до н.э. - III в. н.э. (возможно, начало IV в. н.э.).

3. Этно-культурные и исторические интерпретации

В региональном и историческом контекстах упомянутые материалы имеют прямое отношение к государству Канцзюй (Кангюй) и иным племенным объединениям (сарматы, сюнну, усунь), входящих в состав Кангюй, или имеющих с ним экономические, политические и культурные контакты. В этой связи заслуживает внимания факт обнаружения монеты чекана Вима I Такто, свидетельствующий о том, что северо-восточные границы Великой Кушанской империи простирались в то время до Кангюй. Это объективно предполагает наличие экономических, культурных, и, возможно политических контактов между двумя мощными государствами древности. Кроме всего, находка этой монеты важна ещё и тем, что она выступает в роли аргументированного хроно- индикатора как для строительного горизонта кангюйского периода (хум со знаком), так и для фрагмента культобинского (согдийского, кангюйского) письма на керамических кирпичахтаблицах, обнаруженного здесь же.

Следует отметить, что исследуемые артефакты, полученные из городища Культобе арысского и катакомб могильников Культобе 2, Кылышжар, в этно-культурном плане по нескольким параметрам (обряд погребения, оружие, изделия из египетского фаянса, знаки) уверенно связываются с сарматами. Присутствие как европейских (так азиатских) сарматов на территории Южного Казахстана на рубеже эр и в первые века н.э. в настоящее время в научных кругах казахстанских исследователей не вызывает сомнения [Подушкин, 2000, с. 150-153; 2010, 207-217].

Что касается находки 16-го фрагмента уникальной письменности на обожжённых кирпичах-таблицах городища Культобе арысского, то она интересует нас только в связи с упоминанием в одном из текстов этого письма «людей шатров» (т.е. номадов), которые имели косвенную причастность к основанию города, причём в качестве этих «людей шатров» вполне могли выступать сарматы [Sims-Williams, Grenet, Podushkin, 2007, c. 1006-1034].

\section{ЛИТЕРАТУРА}

1. Алексеева Е.М. Античные бусы Северного Причерноморья. САИ. Вып. Г 1-12, М.: Наука, 1975. 104 с.

2. Алексеева E.M. Бусы и подвески // Античные государства Северного Причерноморья. М.: Наука, 1984. С. 237-239.

3. Горбунова Н.Г. О вооружении среднеазиатских скотоводов (II (III?) в. до н.э. V в. н.э.) // РА. 2000. № 2. С. 40-51.

4. Обельченко О.В. Агалыксайские курганы // ИМКУ. Ташкент, 1972. Вып. 9. C. $56-72$.

5. Обельченко O.В. Курганы в окрестностях Самарканда // Афрасиаб. Ташкент: АН УзбССР, 1973. Вып. II. С. 157-172. 
6. Обельченко О.В. Мечи и кинжалы из Согда // СА. 1978. № 4. С. 115-127.

7. Литвинский Б.А. Среднеазиатские железные наконечники стрел // СА. 1965. № 2. C. 75-91.

8. Литвинский Б.А., Седов А.В. Культы и ритуалы Кушанской Бактрии. М.: Наука, 1984. 240 с.

9. Максимова А.Г., Мерщчиев М.С., Вайнберг Б.И., Левина Л.М. Древности Чардары. Алма-Ата: Наука, 1968. 258 с.

10. Малашев В.Ю., Яблонский Л.Т. Степное население Южного Приуралья в позднесарматское время (по материалам могильника Покровка 10). М.: Восточная литература, 2008. 365 с.

11. Мотеева O.H. Египетский фаянс в сарматских погребениях Нижнего Поволжья // Нижневолжский археологический вестник. 2010. Вып. 11. С. 147-169.

12. Мошкова М.Г. Среднесарматская культура // Археология СССР. Степи европейской части СССР в скифо-сарматское время. М.: Наука, 1989а. С. 177-191.

13. Мошкова М.Г. Позднесарматская культура // Археология СССР. Степи европейской части СССР в скифо-сарматское время. М.: Наука, 1989б. С. 191-202.

14. Подушкин А.Н. Арысская культура Южного Казахстана IV в. до н.э. - VI в. н.э. Туркестан, 2000. 202 с.

15. Подушкин А.Н. Сарматы в Южном Казахстане // Древние культуры Евразии: матер. междунар. научн. конф., посвящ. 100-летию А.Н. Бернштама. СПб.: ИИМК PAH, 2010. C. 207-217.

16. Ртвеладзе Э.В. Древние и средневековые монеты историко-культурных областей Узбекистана. Ташкент, 2002. Т. I. 304 с.

17. Симоненко А.В. Сарматские всадники Северного Причерноморья. СПб.: Факультет филологии и искусств СПбГУ; Нестор-История, 2010. 328 с.

18. Скрипкин А.С. Азиатская Сарматия. Проблемы хронологии и её исторический аспект. Саратов: изд-во Саратовского ун-та, 1990. 299 с.

19. Хазанов А.М. Очерки военного дела сарматов. М.: Наука, 1971. 172 с.

20. Sims-Williams N., Grenet F., Podushkin A. Les plus anciens monuments de la langue sogdienne: les inscriptions de Kultobe au Kazakhstan // Academie des Inscription \& Belles. Paris, 2007. C. 1006-1034.

\section{Сведения об авторе:}

Подушкин Александр Николаевич - доктор исторических наук, профессор кафедры Истории Казахстана и мира, Южно-Казахстанский государственный педагогический университет (г. Шымкент, Казахстан); p_a_n_alex@mail.ru

\section{6-2017 ЖЫЛДАРДАҒЫ АРЫС КУЛТӨБЕСІНДЕГІ, КУЛТӨБЕ ЖӘНЕ ҚЫЛЫШЖАР ҚАБІРЛЕРІНДЕГІ АРХЕОЛОГИЯЛЫҚ ЖҰМЫСТАР}

\section{А.Н. Подушкин}

Мақалада арыстық Күлтөбе көне қалашығының жаңа археологиялық кешендерін, Күлтөбе 2 және Қылышжардың жерлеу алаңдарының 2016-2017 жылдардағы жұмыстарының нәтижесінде алынған катакомбаларды талдауға арналған. Табылған олжалардың толық сипаттамасы келтірілген, зерттелетін ескерткіштердің хронологиясы мен этномәдени бірлестігі мәселелері қамтылып, олардың Қаңлы мемлекетімен байланыстыруға және б.д.д. I ғасыр б.д. III ғасырмен мерзімдеуге мүмкіндік береді.

Түйін сөздер: археология, Оңтүстік Қазақстан, Арыс мәдениеті, катакомб қабірлері, сарматтар, қаңлы, Күлтөбе жазбалары 
Подушкин A.H. Археологические работы на городище Культобе арысском, могильниках Культобе...

\section{ARCHAEOLOGICAL WORK ON THE SITE KULTOBE ARYSS, BURIAL GROUNDS KULTOBE AND KYLYSHJAR IN 2016-2017}

\section{A.N. Podushkin}

The article is devoted to the analysis of new archeological complexes of the ancient settlement of Kultobe Aryss, the catacombs of the burial grounds of Kultobe 2 and Kylyshjar, obtained as a result of works 2016-2017. A complete description of the artifact material is given, the issues of chronology and ethno-cultural affiliation of the studied monuments are covered, which allow them to be associated with the Kangyu state and the I century BC - III century AD.

Keywords: archaeology, Southern Kazakhstan, Arys culture, catacomb burials, sarmatians, Kangyu, Kultobe writing

\section{REFERENCES}

1. Alekseeva, Ye. M. 1975. Antichnye busy Severnogo Prichernomorya. Svod arheologicheskih istochnikov (Antique beads of the Northern Black Sea. Archaeological sources), Г1-12. Moscow: Nauka Publ. (in Russian).

2. Alekseeva, Ye. M. 1984. In Antichnye gosudarstva Severnogo Prichernomorya (Antique states of the Northern Black Sea region). Moscow: Nauka Publ., 237-239 (in Russian).

3. Gorbunova, N. G. 2000. In Rossiiskaya arheologiya (Russian Archaeology), 2, 4051 (in Russian).

4. Obelchenko, O. V. 1972. In Istoriya material'noj kul 'tury Uzbekistana (The history of material culture of Uzbekistan), 9, 56-72 (in Russian).

5. Obelchenko, O. V. 1973. In Afrasiab, II. Tashkent: UzbekSSR Academy of Sciences Publ., 157-172 (in Russian).

6. Obelchenko, O. V. 1978. In Sovetskaya arheologiya (Soviet archaeology), 4, 115127 (in Russian).

7. Litvinskiy, B. A. 1965. In Sovetskaya arheologiya (Soviet archaeology), 2, 75-91 (in Russian).

8. Litvinskiy, B. A., Sedov, A.V. 1984. Kulty i ritualy Kushanskoy Baktrii (The cults and rituals of Kushan Bactria). M.: Nauka Publ. (in Russian).

9. Maksimova, A. G., Mershchiev, M. S., Vaynberg, B. I., Levina, L. M. 1968. Drevnosti Chardary (Antiquities of Chardara). Alma-Ata: Nauka Publ. (in Russian).

10. Malashev, V. Yu, Yablonskiy, L. T. 2008. Stepnoe naselenie Yuzhnogo Priuralya v pozdnesarmatskoe vremya (po materialam mogilnika Pokrovka 10) (Steppe population of the Southern Urals in the Late Sarmatian time (according to the materials of the Pokrovka 10 burial ground)). Moscow: "Vostochnaya literature" Publ. (in Russian).

11. Mosheeva, O. N. 2010. In Nizhnevolzhskiy arkheologicheskiy vestnik (Lower Volga archaeological bulletin), 11, 147-169 (in Russian).

12. Moshkova, M. G. 1989a. In Arkheologiya SSSR. Stepi evropeyskoy chasti SSSR v skifo-sarmatskoe vremya (Archaeology of the USSR. The steppes of the European part of the USSR in the Scythian-Sarmatian time). Moscow: "Nauka" Publ., 177-191 (in Russian).

13. Moshkova, M. G. 1989b. In Arkheologiya SSSR. Stepi evropeyskoy chasti SSSR v skifo-sarmatskoe vremya (Archaeology of the USSR. The steppes of the European part of the USSR in the Scythian-Sarmatian time). Moscow: "Nauka" Publ., 191-202 (in Russian).

14. Podushkin, A. N. 2000. Arysskaya kultura Yuzhnogo Kazakhstana IV v. do n.e. VI v. n.e. (Arys culture of southern Kazakhstan IV century BC-VI century AD). Turkestan (in Russian).

15. Podushkin, A. N. 2010. In Alyokshin, V. A., Kircho, L. B., Sokolova, L. A., Stegantseva, V. Ya. Drevnie kultury Evrazii (k 100-letiyu A.N. Bernshtama) (Ancient cultures of 
Eurasia (to 100th anniversary of Bernshtam, A. N.). Sankt-Petersburg: Institute of Material Culture History RAN, 207-217 (in Russian).

16. Rtveladze, E. V. 2002. Drevnie i srednevekovye monety istoriko-kulturnykh oblastey Uzbekistana (Ancient and medieval coins of historical and cultural regions of Uzbekistan), I. Tashkent (in Russian).

17. Simonenko, A. V. 2010. Sarmatskie vsadniki Severnogo Prichernomorya (Sarmatian horsemen of the Northern Black Sea). Sankt-Petersburg: Faculty of Philology and Arts, St.Petersburg State University; "Nestor History" Publ. (in Russian).

18. Skripkin, A. S. 1990. Aziatskaya Sarmatiya. Problemy khronologii i ee istoricheskiy aspekt (Asian Sarmatia. Problems of chronology and its historical aspect). Saratov: Saratov University Publ. (in Russian).

19. Khazanov, A. M. 1971. Ocherki voennogo dela sarmatov (Sketches of military affairs of the Sarmatians). Moscow: Nauka, 172 s. (in Russian).

20. Sims-Williams, N., Grenet, F., Podushkin, A. 2007. In Academie des Inscription \& Belles. Paris, 1006-1034.

\section{About the Author:}

Podushkin Alexander N. Doctor of History, Professor of the Department History of Kazakhstan and the World, South Kazakhstan State Pedagogical University, p_a_n_alex@mail.ru

\footnotetext{
Мүдделер қақтығысы туралы ақпаратты ашу. Автор мүдделер қақтығысының жоқтығын мәлімдейді. / Раскрытие информации о конфликте интересов. Автор заявляет об отсутствии конфликта интересов. / Disclosure of conflict of interest information. The author claims no conflict of interest.

Мақала туралы ақпарат / Информация о статье / Information about the article. Редакцияға түсті / Поступила в редакцию / Entered the editorial office: 28.05.2018. Рецензенттер мақұлдаған / Одобрено рецензентами / Approved by reviewers: 04.06.2018. Жариялауға қабылданды / Принята к публикации / Accepted for publication: 11.06.2018.
} 